International Journal of Mathematical Research

2013 Vol. 2, No. 4, pp. 23-36

$\operatorname{ISSN}(e): 2306-2223$

$\operatorname{ISSN}(p): 2311-7427$

DOI: $10.18488 /$ journal.24/2013.2.4/24.4.23.36

(C) 2013 Conscientia Beam. All Rights Reserved.

(CrossMark

\title{
MATHEMATICAL ANALYSIS OF THE IMPACT OF REAL EXCHANGE RATE ON OUTPUT GROWTH AND INFLATION: THE CASE OF TANZANIA ZANZIBAR
}

\author{
Khamis Khalid Said ${ }^{1}$--- Eliab Luvanda ${ }^{2}$--- Estomih S. Massawe ${ }^{3}$ \\ ${ }^{1, s}$ Mathematics Department, University of Dar es Salaam, Tanzania \\ ${ }^{2}$ Department of Economics, University of Dar es Salaam, Tanzania
}

\begin{abstract}
This paper examines the dynamic relationship between stationary time series for the impact of real exchange rate on output growth and inflation in Tanzania: Zanzibar using vector autoregressive (VAR) model. The impact of the real exchange rate on economic performance in Tanzania using VAR approach shows that the main sources of variance decomposition in the volume of tourism and inflation are in their own shocks. Impulse response functions analysis show that the response generated by itself at short run and vanishing at the long run, and the inflation and number of tourism has no instantaneous impact on the first difference of real exchange rate. Variance decomposition analysis show that the impact of number of tourism arrival on real exchange rate increases monotonically to the long-run. Thus analysis show that 98 percent of the variance of number of tourism arrival is generated by its own innovations, while only 87 percent of the variance of inflation is generated by its own innovations and about 99 percent of the variance of real exchange rate generated by its own innovations. Furthermore; the real exchange rate is Granger causal to both inflation and number of tourism, while the number of tourism is Granger Causal to the inflation.
\end{abstract}

Keywords: Real exchange rate, Output growth, Inflation.

Received: 24 April 2013/ Revised: 13 June 2013/ Accepted: 18 June 2013/ Published: 22 June 2013

\section{INTRODUCTION}

The real exchange rate has been considered by the government as an important macroeconomic instrument for ensuring low inflation rate and a stable financial system, promoting exports, controlling imports, and enhancing economic growth. To assess the soundness of the reform policies in the exchange rate regime, it is worthy to analyze the impact of the changes in real exchange rate on macroeconomic indicators [1]. 
The effect of the real exchange rate on output growth is extremely important for developing countries and is a subject of great debate among economists. The controversy concerns the effect to the economy from depreciation in the real exchange rate. The orthodox view sees this as an expansionary with the substitution of imports with home goods and increased exports putting the economy on a path of greater sustained growth [2].

Currency exchange rates tend to be affected by macroeconomic variables, such as the major economic indicators released by governments at fixed intervals. For instance, the Gross Domestic Product (GDP), unemployment rate, and even current interest rates (prime rates) can all affect currency exchange rates. However, it is possible for major political events (such as elections, wars, etc.) to also affect currency exchange rates. Even commodities (gold, oil prices, wheat, etc.) may affect the exchange rates among countries. Any changes in exchange rates will have a great impact on the economy (www. investorguide.com, retrieved on $29^{\text {th }}$, September 2010).

In the system of floating exchange rates, exchange rate fluctuations can have a strong impact on the level of prices through the aggregate demand (AD) and aggregate supply (AS) [3]. On the aggregate supply, depreciation (devaluation) of domestic currency can affect the price level directly through imported goods that domestic consumers pay. However, this condition occurs if the country is the recipient countries of international prices (international price taker). Non direct influence from the depreciation (devaluation) of currency against the price level of a country can be seen from the price of capital goods (intermediate goods) imported by the manufacturer as an input. The weakening of exchange rate will raise the price of inputs, thus contributing to a higher cost of production. Manufacturers will certainly increase the cost to the price of goods that will be paid by consumers. As a result, the price level aggregate in the country increases or if it continues to increase it will cause inflation [3].

For open-economy countries, inflation comes from domestic factors (internal pressure) and also overseas factors (external pressure). The sources of external factors are the increase in the world commodity prices or real exchange rate fluctuation. The influence of real exchange rate towards inflation itself depends on the choice of real exchange rate regime in the country. Real exchange rate system has an important role in reducing or minimizing the risk of fluctuations in exchange rates, which will have an impact on the economy [3].

A key assumption behind the medium-term strategy is that there is no long-run trade off between inflation and the level of output growth. This assumption is also known as "the long-run neutrality of money" or the "natural rate hypothesis" (NRH) [4]. Thus expansionary monetary policies may temporarily increase output growth and lower unemployment, but the economy will eventually return to the natural rate of unemployment at a higher rate of inflation. Conversely, deflationary policies will over a certain period reduce output growth as well as the rate of inflation, but at the end only the reduction in inflation will remain as the economy again returns to its natural rate [4].

In exchange-rate-based stabilization programs, there are, especially in the initial phases, strong output growth periods, which indicate that the causality between output growth and the 
real exchange rate runs from the former to the later. In this kind of stabilization program, domestic demand is pushed with the implementation of the program, which will increase the price of non-tradable goods where the price of tradable goods is fixed or exhibits less increase than non-tradable due to the pegged exchange rate regime; thus, the real exchange rate appreciates [5].

The gross domestic product (GDP) or gross domestic income (GDI) is a measure of a country's overall economic output. It is the market value of all finished goods and services produced in a country during a certain period of time. Note that we only include finished goods and services; that is, anything that is sold directly to the consumer. Real GDP growth is defined as the percentage change in the real GDP. The real growth tells us how much the economy has grown during a particular period when the effect of inflation is removed. To eliminate (remove) the effect of inflation we divide GDP by a price index and we define real GDP as GDP divided by a price index [6].

Real exchange rate movements could affect prices paid by the domestic buyers of imported goods directly. In an open small economy (an international price taker), when the currency depreciates it will result in higher import prices and vice versa. The potentially higher cost of imported inputs associated with an exchange rate depreciation increases marginal cost and leads to higher prices of domestically produced goods [7].

Exchange rate variations can also affect aggregate demand. To a certain extent, exchange rate depreciations (appreciations) increase (decrease) foreign demand for domestic goods and services, causing increase (decrease) in net exports and hence aggregate demand [7].

Traditional views such as the elasticities, absorption, and the Keynesian approach assert that devaluations have positive effect on output growth. The elasticities approach states that devaluation will improve trade balance as long as the Marshall Lerner condition is satisfied. According to the absorption approach, through its expenditure switching and expenditure reducing effects, a devaluation will generate an increase in real output. The Keynesian approach, in which output is assumed to be demand determined and the economy operates below its potential, full-employment condition - states that a devaluation will have a positive impact on output and employment. The monetary approach, however, argues that real exchange rate changes influence real magnitudes mainly through the real balance effect in the short-run but leave all variables unchanged in the long run [8].

In contrast, there are some various channels that explain the contractionary effect of devaluations such as nominal rigidities in the economy, balance-sheet effects, capital account problems, weakening confidence, and associated economic policies [9]

In this paper therefore it is intended to formulate and analyze mathematical model for the impact of changes in real exchange rate on output growth and inflation in Tanzania. 


\section{THE AUTOREGRESSION MODEL}

Let $y_{t}$ denote the value of the variable of interest in period $t$. Then for a forecast with period $t+h$, achieved at the end of period $t$, may have the form

$$
\hat{y}_{t+h}=f\left(y_{t}, y_{t-1}, \ldots\right)
$$

Consider a univariate time series $y_{t}$ and a forecast with a period $h=1$. If $f\left(y_{t}, y_{t-1}, \ldots\right)$ is a linear function, then we have

$$
\hat{y}_{t+h}=v+\alpha_{1} y_{t}+\alpha_{2} y_{t-1}+\ldots
$$

Consequently the vector autoregresion model of order $p(\operatorname{VAR}(p))$ is given by

$$
\mathbf{y}_{t}=\mathbf{v}+\sum_{i=1}^{p} \mathbf{A}_{i} \mathbf{y}_{t-i}+\mathbf{u}_{t} \quad t=0,1,2,3, \cdots
$$

where

$$
\mathbf{A}_{i}=\left(\begin{array}{ccc}
\alpha_{11, i} & \cdots & \alpha_{1 K, i} \\
\vdots & \ddots & \vdots \\
\alpha_{K 1, i} & \cdots & \alpha_{K K, i}
\end{array}\right)
$$

$u_{t}$ is a forecast error (white noise error term), where $E\left(u_{t} u_{s}{ }^{\prime}\right)=0$ for $s \neq t$. The covariance matrix $\boldsymbol{\Omega}_{u}$ is assumed to be non-singular.

The quantities $y_{t}, y_{t-1}, \ldots, y_{t-p}$, and $u_{t}$ are random variables. It is assumed that the forecast error $\boldsymbol{u}_{\boldsymbol{t}}$ of different periods are uncorrelated. Equation (2) can be written in the form

$$
\left(\begin{array}{c}
D R E R_{t} \\
I_{t} \\
N_{t}
\end{array}\right)=\left(\begin{array}{c}
v 1 \\
v 2 \\
v 3
\end{array}\right)+\sum_{i=1}^{p}\left(\mathbf{A}_{i} \times\left(\begin{array}{c}
D R E R_{t-i} \\
I_{t-i} \\
N_{t-i}
\end{array}\right)\right)+\left(\begin{array}{l}
u_{1 t} \\
u_{2 t} \\
u_{3 t}
\end{array}\right)
$$

where $I$ is the inflation, $N$ is the number of tourism arrival and $D R E R$ is the first difference of real exchange rate.

We shall use the the Augmented Dickey - Fuller (ADF) test shown in table 1 below in the analysis of the model. 


\section{DATA ANALYSIS}

Data used in the analysis of the $\operatorname{VAR}(p)$ model were obtained from the Ministry of Finance and Economics (Zanzibar), Bank of Tanzania (B.O.T), Office of the Chief Government Statistician and Commission for Tourism (Zanzibar). Figure 1 below shows the real exchange rates in Zanzibar with time for the years 2000 to 2010.

Figure-1. Real Exchange Rate with Time

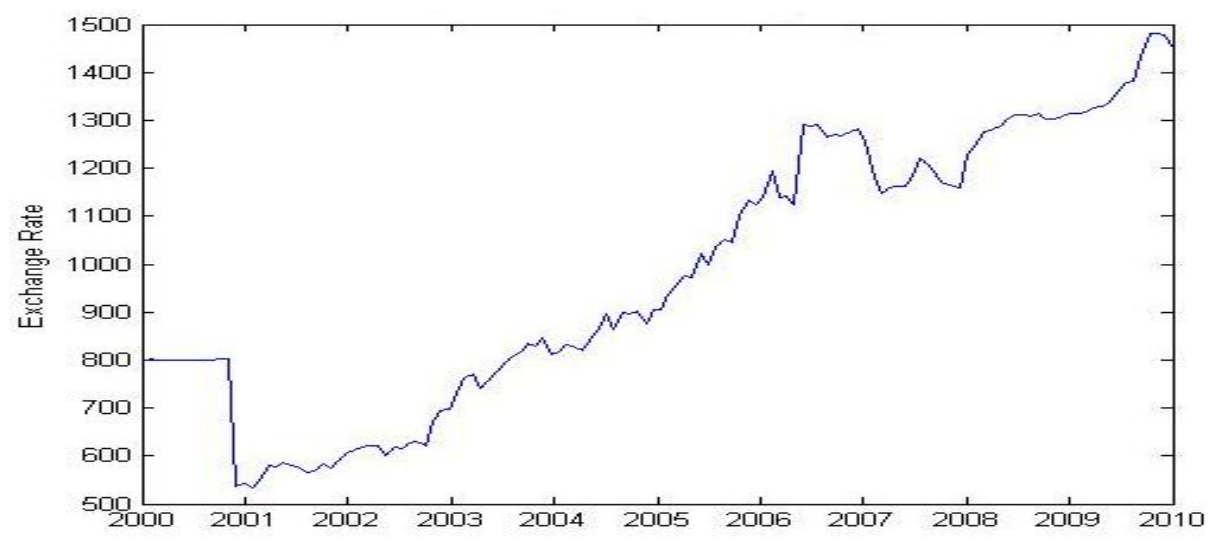

In the year 2000 the real exchange rate was almost stable, changing from TZS 797.33 per USD in January 2000 to TZS 803.54 per USD in December 2000. In January 2001 the real exchange rate decreased to TZS 535.59 per USD. From March 2001 the real exchange rate increased again to up to TZS 1449.36 per USD in December 2010.

Table-1. ADF test Result

\begin{tabular}{llll}
\hline \multirow{2}{*}{ Variable } & \multicolumn{2}{c}{ ADF test Statistic } & \multirow{2}{*}{ Remarks } \\
\cline { 2 - 4 } & Level & First Difference & \\
\hline Real Exchange Rate & -2.99 & -11.47 & Stationary at first Difference \\
\hline Inflation & -6.46 & - & Stationary \\
\hline Number of Tourism Arrival & -8.42 & - & Stationary \\
\hline
\end{tabular}

Critical values are $-4.0309,-3.4447$ and -3.1469 at $1 \%, 5 \%$ and $10 \%$ significant level, respectively. It can be seen that the real exchange rate is stationary at the first difference. Figure 1 shows that the real exchange rate is not stationary.

Figure 2 below shows the time series trend of the $1^{\text {st }}$-difference of real exchange rate with time. 
Figure-2. $1^{\text {st }}$-difference graph of real exchange rate with time

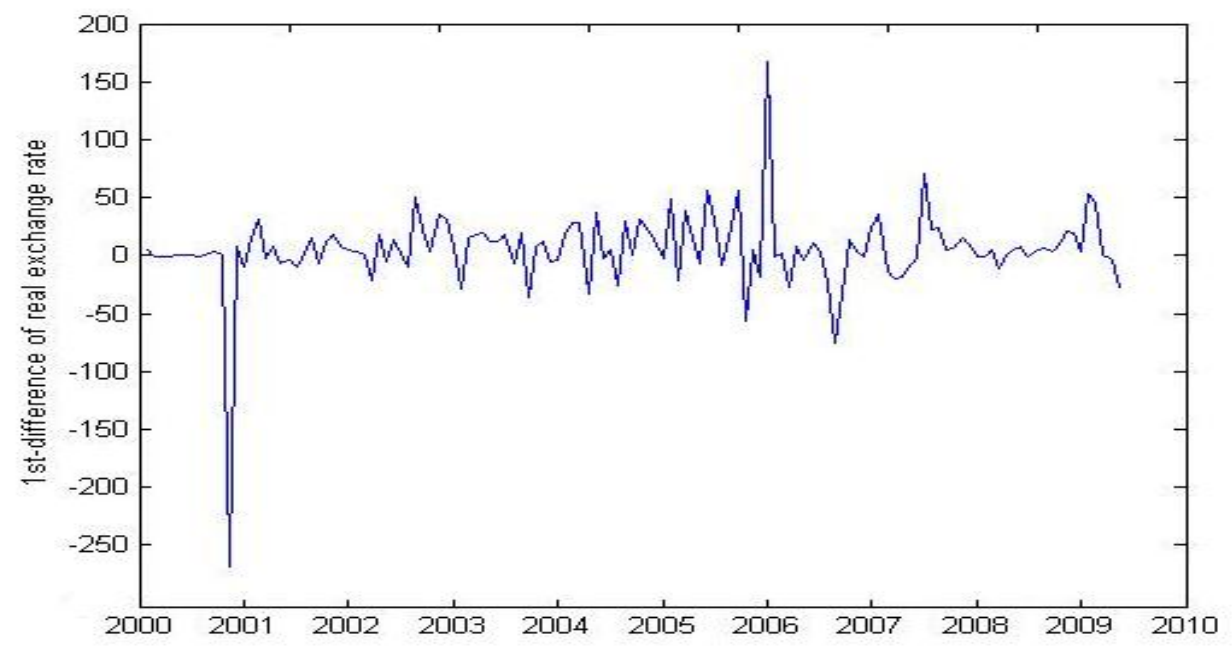

From figure 2 it is seen that the series is stationary at the first difference.

The month to month inflation trend is stochastically distributed over time. It ranges from 2.6 to +5.6 for the monthly period of eleven years $(2000-2010)$ as shown in figure 3 below.

Figure-3. Inflation variations with time

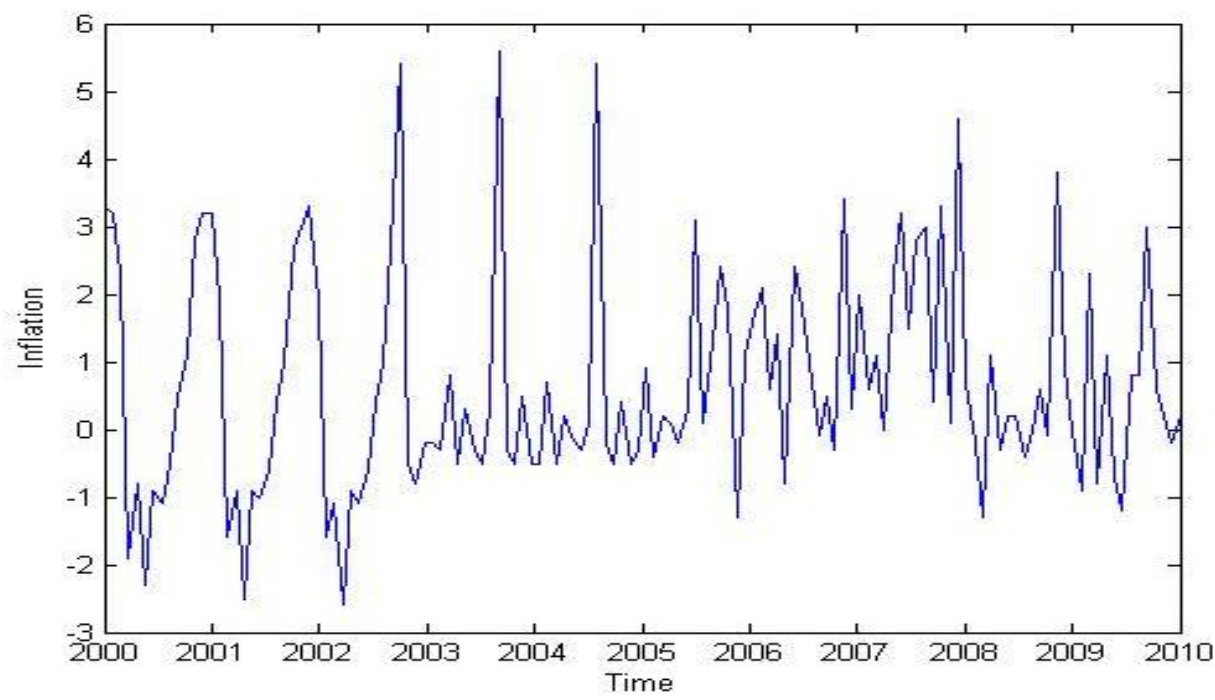

Table 1 reveals that the inflation is stationary.

Figure 4 below shows the trend of the tourism arrival in Zanzibar in the years 2000-2010 
Figure-4. Number of Tourism arrival with Time

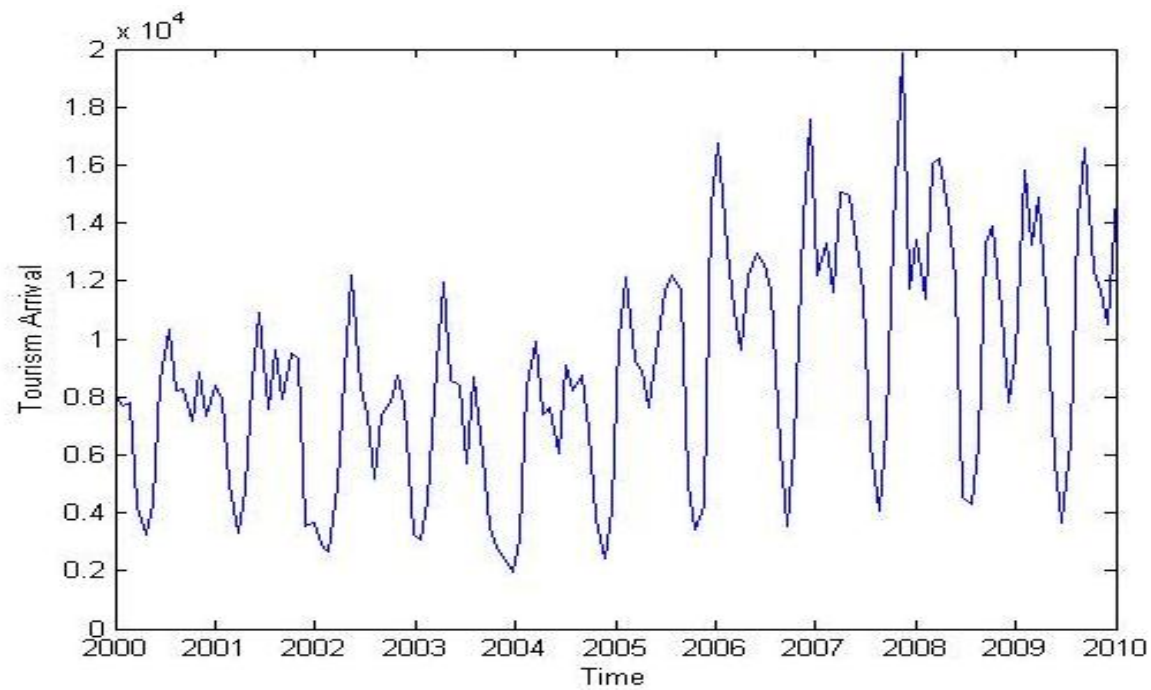

It is seen that tourism is stochastically distributed and that it is stationary over time as revealed from table 1.

\subsection{Vector Autoregression Estimates}

Equation (3) above can be expanded up to order two to obtain

$$
\left(\begin{array}{c}
D R E R_{t} \\
I_{t} \\
N_{t}
\end{array}\right)=\left(\begin{array}{c}
v 1 \\
v 2 \\
v 3
\end{array}\right)+\mathbf{A}_{1} \times\left(\begin{array}{c}
D R E R_{t-1} \\
I_{t-1} \\
N_{t-1}
\end{array}\right)+\mathbf{A}_{2} \times\left(\begin{array}{c}
D R E R_{t-2} \\
I_{t-2} \\
N_{t-2}
\end{array}\right)+\left(\begin{array}{l}
u_{1 t} \\
u_{2 t} \\
u_{3 t}
\end{array}\right)
$$

The Vector Autoregression Estimates from EViews software package estimates the deterministic component variable ' $v_{t}{ }^{\prime}$ and matrix coefficients ' $\mathbf{A}_{i}{ }^{\prime}$ as follow

$$
\begin{aligned}
& \left(\begin{array}{l}
v 1 \\
v 2 \\
v 3
\end{array}\right)=\left(\begin{array}{l}
0.92 \\
-0.33 \\
4062.16
\end{array}\right) ; \mathbf{A}_{1}=\left(\begin{array}{lcl}
-0.01 & -1.15 & 0.00 \\
0.00 & 0.10 & 0.00 \\
-1.54 & 142.00 & 0.92
\end{array}\right) \text { and } \\
& \mathbf{A}_{2}=\left(\begin{array}{lcc}
0.04 & 0.72 & 0.00 \\
0.00 & 0.10 & 0.00 \\
-1.26 & -337.69 & -0.36
\end{array}\right)
\end{aligned}
$$

and therefore the VAR model is given as

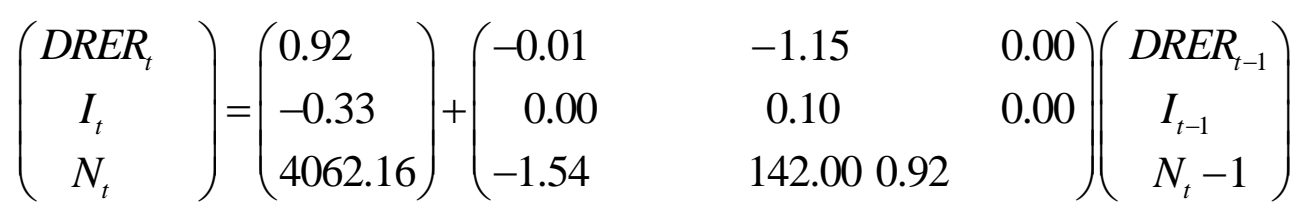




$$
+\left(\begin{array}{llll}
0.04 & 0.72 & 0.00 \\
0.00 & 0.10 & & 0.00 \\
-1.26 & -337.69 & -0.36 &
\end{array}\right)\left(\begin{array}{c}
D R E R_{t-2} \\
I_{t-2} \\
N_{t-2}
\end{array}\right)+\left(\begin{array}{l}
u_{1 t} \\
u_{2 t} \\
u_{3 t}
\end{array}\right)
$$

with covariance matrix $\boldsymbol{\Omega}_{u}=\left(\begin{array}{lll}1203.36 & -5.43 & 2519.07 \\ -5.43 & 2.58 & 1308.91 \\ 2519.07 & 1308.91 & 15640081\end{array}\right)$

The autocovariance matrices are defined as

$$
\Gamma_{y}(\tau)=E\left[\left(y_{t}-\mu\right)\left(y_{t-\tau}-\mu\right)^{\prime}\right]
$$

If we let $E\left(y_{t}\right)=\mu=0$ we obtain

$$
\begin{aligned}
\boldsymbol{\Gamma}_{y}(\tau)=E\left[y_{t} y_{t-\tau}{ }^{\prime}\right] & =\mathbf{A}_{1} E\left[y_{t-1} y_{t-\tau}{ }^{\prime}\right]+\mathbf{A}_{2} E\left[y_{t-2} y_{t-\tau}{ }^{\prime}\right] \\
& +A_{p} E\left[y_{t-p} y_{t-\tau^{\prime}}\right]+E\left[u_{t} y_{t-\tau^{\prime}}\right]
\end{aligned}
$$

This leads to the equations determining the autocovariance matrices for $\tau \geq 0$.

For $\tau>0$, we have

$$
\boldsymbol{\Gamma}_{y}(\tau)=\mathbf{A}_{1} \Gamma_{y}(\tau-1)+\mathbf{A}_{2} \Gamma_{y}(\tau-2)+\mathbf{A}_{3} \Gamma_{y}(\tau-3)+\cdots+\mathbf{A}_{p} \Gamma_{y}(\tau-p) .
$$

For $\tau=0$, we have

$$
\boldsymbol{\Gamma}_{y}(0)=\mathbf{A}_{1} \Gamma_{y}(-1)+\mathbf{A}_{2} \Gamma_{y}(-2)+\mathbf{A}_{3} \Gamma_{y}(-3)+\cdots+\mathbf{A}_{p} \Gamma_{y}(-p)+\boldsymbol{\Omega}_{u}
$$

Which gives

$$
\boldsymbol{\Gamma}_{y}(0)=\mathbf{A}_{1} \Gamma_{y}(1)^{\prime}+\mathbf{A}_{2} \Gamma_{y}(2)^{\prime}+\mathbf{A}_{3} \Gamma_{y}(3)^{\prime}+\cdots+\mathbf{A}_{p} \Gamma_{y}(p)^{\prime}+\boldsymbol{\Omega}_{u}
$$

The individual correlation coefficients are given as

$$
\rho_{i j}(\tau)=\frac{\gamma_{i j}(\tau)}{\sqrt{\gamma_{i i}(0) \cdot \gamma_{j j}(0)}} \text { for } i, j=1,2,3, \cdots, k
$$

The autocorrelation matrices are therefore given by

$$
\mathbf{R}_{y}(\tau)=\mathbf{D}^{-1} \Gamma_{y}(\tau) \mathbf{D}^{-1}
$$

where $D^{-1}$ is the diagonal matrix 


$$
\mathbf{D}^{-1}=\left(\begin{array}{cccc}
\frac{1}{\sqrt{\gamma_{11}(0)}} & 0 & \cdots & 0 \\
0 & \frac{1}{\sqrt{\gamma_{22}(0)}} & \cdots & 0 \\
\vdots & \vdots & \ddots & \vdots \\
0 & 0 & \cdots & \frac{1}{\sqrt{\gamma_{k k}(0)}}
\end{array}\right)
$$

where $\gamma_{11}(0), \gamma_{22}(0), \gamma_{33}(0), \cdots, \gamma_{k k}(0)$ of $\quad \boldsymbol{\Gamma}_{y}(0)$ are the variances of $y_{1 t}, y_{2 t}, \cdots, y_{k t} \cdot \gamma_{11}(\tau)$, are the variances of $y_{1 t}, y_{2 t}, \cdots, y_{k t}$ which can be determined.

Equations (7) and (8) leads to

$$
\boldsymbol{\Gamma}_{y}(0)=\mathbf{A}_{1} \Gamma_{y}(0) \mathbf{A}_{1}^{\prime}+\boldsymbol{\Omega}_{u}
$$

Let the autocovariance matrix be given by

$$
\boldsymbol{\Gamma}_{y}(0)=\left(\begin{array}{lll}
\gamma_{11} & \gamma_{12} & \gamma_{13} \\
\gamma_{21} & \gamma_{22} & \gamma_{23} \\
\gamma_{31} & \gamma_{32} & \gamma_{33}
\end{array}\right) .
$$

By the matrix $A_{1}$ and covariance matrix $\Omega_{u}$ above, we get the following system of linear equations:

$$
\begin{aligned}
& 0.99 \gamma_{11}-0.023 \gamma_{21}-1.32 \gamma_{22}=1203.36 \\
& 1.001 \gamma_{21}+0.115 \gamma_{22}=-5.43 \\
& 1.01 \gamma_{31}-0.01 \gamma_{11}-0.35 \gamma_{21}+163.3 \gamma_{22}+1.06 \gamma_{32}=2519.07 \\
& 0.99 \gamma_{22}=2.58 \\
& 0.91 \gamma_{32}+0.15 \gamma_{21}-14.2 \gamma_{22}=1308.91
\end{aligned}
$$$$
0.15 \gamma_{33}-2.37 \gamma_{11}+437.36 \gamma_{21}+2.83 \gamma_{31}-20164 \gamma_{22}-261.28 \gamma_{32}=15640081
$$ 
The variances $\gamma_{11}, \gamma_{22}$ and $\gamma_{33}$ of DRER, I and $N$ as well as their covariance matrix $\gamma_{12}, \gamma_{13}$ and $\gamma_{23}$ in the system (13), is solved by MAPLE software to obtain

$\gamma_{11}=1206.79, \gamma_{22}=2.61, \quad \gamma_{33}=1047136856, \quad \gamma_{12}=-5.72, \gamma_{13}=535.86 \quad$ and $\gamma_{23}=1483.26$

Thus;

The instantaneous correlation between $D R E R$ and $I$ is given by

$$
\rho_{12}(\tau)=\frac{\gamma_{12}(\tau)}{\sqrt{\gamma_{11}(0) \cdot \gamma_{22}(0)}}=\frac{-5.72}{\sqrt{1206.79 \times 2.61}}=-0.1019
$$

The instantaneous correlation between $D R E R$ and $N$ is given by

$$
\rho_{13}(\tau)=\frac{\gamma_{13}(\tau)}{\sqrt{\gamma_{11}(0) \cdot \gamma_{33}(0)}}=\frac{535.86}{\sqrt{1206.79 \times 1047136856}}=0.0015
$$

The instantaneous correlation between I and $N$ is given by

$$
\rho_{23}(\tau)=\frac{\gamma_{23}(\tau)}{\sqrt{\gamma_{22}(0) \cdot \gamma_{33}(0)}}=\frac{1483.26}{\sqrt{2.61 \times 1047136856}}=0.08972
$$

The autocovariance matrix $\boldsymbol{\Gamma}_{y}=\left(\begin{array}{lll}\gamma_{11} & \gamma_{12} & \gamma_{13} \\ \gamma_{21} & \gamma_{22} & \gamma_{23} \\ \gamma_{31} & \gamma_{32} & \gamma_{33}\end{array}\right)$ can be obtained by substituting the values of $\gamma_{i j}$ obtained to get

$$
\Gamma_{y}=\left(\begin{array}{lcc}
1206.79 & -5.72 & 535.86 \\
-5.72 & 2.61 & 1483.26 \\
535.86 & 1483.26 & 104713685.6
\end{array}\right)
$$

By the systems (10) and (11), we have the To get the autocorrelation matrix as

$$
\mathbf{R}_{y}=\left(\begin{array}{ccc}
1 & -0.11 & 0 \\
-0.11 & 1.26 & 0.1 \\
0 & 0.11 &
\end{array}\right)
$$


By the stability i.e. $\operatorname{det}\left(\mathbf{I}-\mathbf{A}_{1} z-\mathbf{A}_{2} z^{2}-\cdots-\mathbf{A}_{p} z^{p}\right)=0$ for $|z|>1$, we have $z_{1}=5.1266, z_{2}=-4.8766, z_{3}=-3.7016, z_{4}=2.7016$ and $z_{5,6}=1.2778 \pm 1.0701 i$, which are obviously absolutely greater than one and thus the VAR model (3) is stable.

\subsection{Granger - Causality test}

The variable $y$ is said to be Granger-caused by the variable $x$ if $x$ helps in the prediction of $y$, or equivalently if the coefficients on the lagged $x$ 's are statistically significant [10]. Twoway causation is frequently used; $x$ Granger causes $y$ and $y$ Granger causes $x$. Table 2 below shows the Granger Causality Test for the time series.

Table-2. Granger Causality Test

\begin{tabular}{|c|c|c|c|}
\hline \multicolumn{4}{|l|}{ Pair wise Granger Causality Tests } \\
\hline \multicolumn{4}{|l|}{ Date: $07 / 10 / 11$ Time: $11: 48$} \\
\hline \multicolumn{4}{|l|}{ Sample: 2000:01 2010:12 } \\
\hline \multicolumn{4}{|l|}{ Lags: 2} \\
\hline Null Hypothesis: & Obs & F-Statistic & Probability \\
\hline Number Of Tourists Does Not Granger Cause Inflation & 130 & 6.74751 & 0.00165 \\
\hline Inflation Does Not Granger Cause Number Of Tourists & & 2.42469 & 0.09266 \\
\hline Real Exchange Rate Does Not Granger Cause Inflation & 130 & 1.13224 & 0.32559 \\
\hline Inflation Does Not Granger Cause Real Exchange Rate & & 0.14145 & 0.86823 \\
\hline $\begin{array}{l}\text { Real Exchange Rate Does Not Granger Cause Number O } \\
\text { Tourists }\end{array}$ & $\mathrm{f}_{130}$ & 11.6855 & $2.2 \mathrm{e}-05$ \\
\hline $\begin{array}{l}\text { Number Of Tourists Does Not Granger Cause Rea } \\
\text { Exchange Rate }\end{array}$ & & 0.24421 & 0.78370 \\
\hline
\end{tabular}

From the table 2 above, we get the following results:

- Inflation does not Granger Causal to Number of Tourists; meaning that the number of tourists is Granger Causal to Inflation,

- Inflation does not Granger Causal to Real Exchange Rate,

- Number of Tourists does not Granger Causal to Real Exchange Rate.

\subsection{Impulse Response}

An impulse response function traces the effect of a one standard deviation shock to one of the innovations on current and future values of the endogenous variables. A shock to the $\mathrm{i}^{\text {th }}$ variable directly affects the $\mathrm{i}^{\text {th }}$ variable, and is also transmitted to all of the endogenous variables through the dynamic structure of the VAR. Figures 5 below shows the impulse response functions with two error bonds. 
Figures-5. Impulse Response Functions
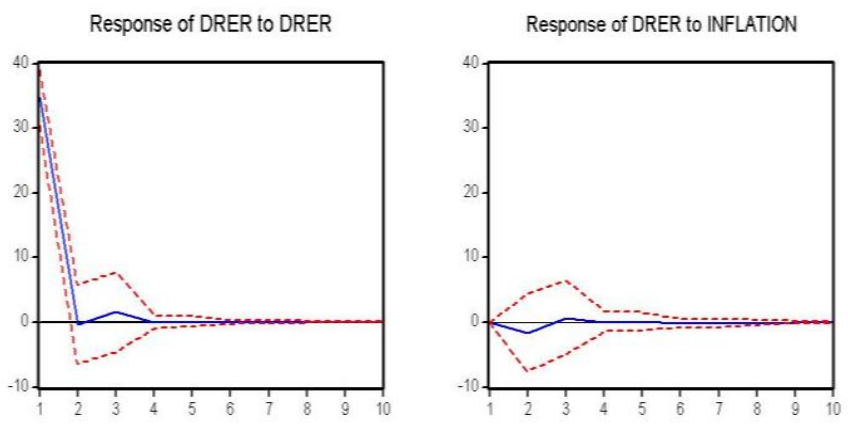

Response of DRER to NO_TOURISM
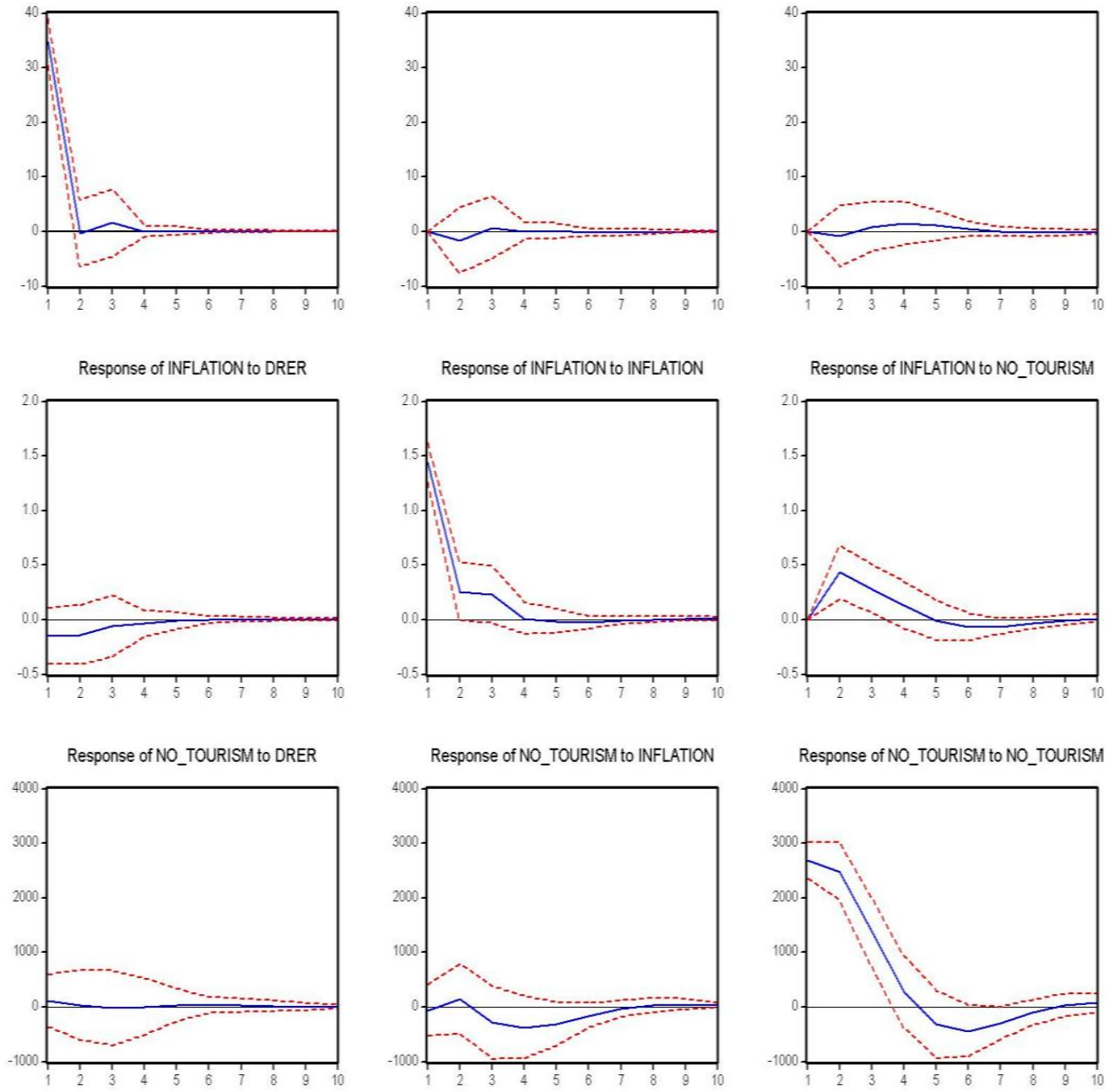

The graphical presentations of the impulse response functions in figures 5 show that the response generated by itself at first period and dying at the long run, and the Inflation and Number of Tourists have no instantaneous impact on DRER. The first value in the impulse response function of DRER on Inflation and number of tourism is zero.

\subsection{Variance Decomposition}

Variance decomposition provides a different method of depicting the system dynamics. Impulse response functions trace the effects of a shock to an endogenous variable on the variables in the VAR. By contrast, variance decomposition decomposes variation in an endogenous variable into the component shocks to the endogenous variables in the VAR. The variance decomposition gives information about the relative importance of each random innovation to the variables in the VAR. Table 3 below shows the Variance decomposition presented in percentages. 
Table-3. Variance Decomposition

\begin{tabular}{lllll}
\hline Periods & Variance Decomposition & DRER & $\mathbf{I}$ & $\mathbf{N}$ \\
\hline \multirow{3}{*}{ 1 period } & DRER & 100.00 & 0.00 & 0.00 \\
\cline { 2 - 5 } & $\mathrm{I}$ & 1.03 & 98.97 & 0.00 \\
\cline { 2 - 5 } & $\mathrm{N}$ & 1.09 & 0.05 & 99.75 \\
\hline \multirow{3}{*}{4 periods } & $\mathrm{DRER}$ & 99.44 & 0.26 & 0.30 \\
\cline { 2 - 5 } & $\mathrm{I}$ & 1.83 & 86.95 & 11.22 \\
\cline { 2 - 5 } & $\mathrm{N}$ & 0.10 & 1.60 & 98.30 \\
\hline \multirow{3}{*}{8 periods } & $\mathrm{DRER}$ & 99.32 & 0.26 & 0.42 \\
\cline { 2 - 5 } & $\mathrm{I}$ & 1.83 & 86.62 & 11.55 \\
\cline { 2 - 5 } 20 periods & $\mathrm{N}$ & 0.11 & 2.36 & 97.53 \\
\cline { 2 - 5 } & $\mathrm{DRER}$ & 99.31 & 0.26 & 0.42 \\
\hline \multirow{2}{*}{ infinity } & $\mathrm{I}$ & 1.83 & 86.61 & 11.56 \\
\cline { 2 - 5 } & $\mathrm{N}$ & 0.11 & 2.37 & 97.50 \\
\cline { 2 - 5 } & $\mathrm{DRER}$ & 99.31 & 0.26 & 0.42 \\
\cline { 2 - 5 } & $\mathrm{I}$ & 1.83 & 86.61 & 11.56 \\
\cline { 2 - 5 } & $\mathrm{N}$ & 0.11 & 2.37 & 97.51 \\
\hline
\end{tabular}

From table 3, it can be seen that, in the first period, it can be seen that there is no instantaneous effect from $\mathrm{N}$ to DRER and I, and also, there is no instantaneous effect from I to DRER. Furthermore, in the first period the variance of DRER is exclusively generated by its own innovations. The impact of $N$ on DRER increases monotonically and in the long-run generates about 0.4 percent of the variance of this variable. Contrary to this, the impact of DRER on $N$, rather strong with 0.2 percent in the first period, decreases over time, and in the long-run generates only about 0.1 percent of the variance of $N$. Thus, 98 percent of the variance of $N$ is generated by its own innovations and only 2 percent by those of $I$, while only 0.1 percent on DRER by the innovation of $N$. Only 87 percent of the variance of $I$ are generated by its own innovations and only 12 percent by those of $N$ and 2 percent of those DRER by the innovation of $I$. Furthermore about 99 percent of the variance of DRER were generated by its own innovations, but only 0.26 percent of $I$ and 0.42 percent of $N$ were generated by the innovations of DRER.

\section{CONCLUSIONS AND RECOMMENDATIONS}

In this paper, the effect of changes in the real exchange rate on the evolution of output and inflation in Tanzania during the period from 2000 to 2010 was studied. A multivariate VAR model was employed to examine the dynamic interrelationship between the variables. The findings revealed that, in Tanzania, there is Granger causality relationships running from the real exchange rate to the both inflation and number of tourists arrival and also the number of tourists arrival is Granger Causal to Inflation.

Impulse response functions analysis showed that the response generated by itself in the short run and dye in the long run. The inflation and volume of tourism has no instantaneous impact on the first difference of real exchange rate, that is, in the first value in the impulse response function of first difference of real exchange rate on inflation is zero and that on volume of tourism is also zero. 
However, results derived from the analysis of forecast error variance decompositions showed that the change in the real exchange rate is not the main source of changes in the volume of Tourism arrival and the price level. The main sources of variation in volume of tourism arrival and price level are the own shocks. The results derived in this study recommends that Tanzania should make more flexible exchange rate regime, or should not insist on controlling the exchange rate while being under pressure of economic integration that forces the exchange rate regime to a more floating one. It is shown in this study that greater flexibility of the exchange rate will help the economy improve its trade balance and increase the volume of tourism arrival, while the inflation situation remains not seriously affected.

Funding: This study received no specific financial support.

Competing Interests: The authors declare that they have no conflict of interests.

Contributors/Acknowledgement: All authors contributed equally to the conception and design of the study.

\section{REFERENCES}

[1] T. Nguyen and F. Seiichi, Impact of the real exchange rate on output and inflation in vietnam: A VAR Approach, Discussion Paper No.0625, 2007.

[2] R. Dornbusch, Open economy macroeconomics: New York, 1988.

[3] A. A. Noer, J. F. Arie and A. Piter, "The relationship between inflation and real exchange rate, comparative study between ASIAN+3, the EU and North America," European Journal of Economics, Finance and Administrative Sciences, ISSN 1450-2887, 2010.

[4] S. A. Palle, Inflation and output: A review of the wage-price mechanism, bank for international settlements (BIS): Monetary and Economic department, Economic Papers No. 24, 1989.

[5] B. Hakan and P. Mehmet, Effects of the real exchange rate on output and inflation: Evidence from Turkey, 2003.

[6] J. Peter, Essential of macroeconomics: Peter Jochumzen \& Ventus Publishing Aps, ISBN 978-87-7681-558-5, 2010 .

[7] Z. Hyder and S. Sardar, Exchange rate pass-through to domestic prices in Pakistan: In State Bank of Pakistan Working Paper, 5. Islamabad: State Bank of Pakistan, 2004.

[8] I. Domac, "Are devaluation contractionary? Evidence from Turkey," Journal of Economic Development, vol. 22, 1997.

[9] P. Krugman and L. Taylor, "Contractionary effects of devaluation," Journal of International Economics, Elsevier, vol. 8 , pp. $445-456,1978$.

[10] C. W. Granger, "Investigating causal relations by econometric mode1s and cross spectral methods," Econometrica, vol. 37, pp. 424-438, 1969. 